\title{
Clinical Profile and Endoscopic Findings in Patients with Upper Gastrointestinal Bleed Attending a Tertiary Care Hospital: A Descriptive Cross-sectional Study
}

\author{
Subash Bhattarai ${ }^{1}$ \\ 'Unit of Medical Gastroenterology, Department of Medicine, Manipal College of Medical Sciences, Pokhara, \\ Nepal.
}

\begin{abstract}
Introduction: Upper gastrointestinal bleeding is a common acute medical emergency. Endoscopy is the gold standard diagnostic and therapeutic tool in the management of upper gastrointestinal bleed. This study was undertaken to address the clinical profile, endoscopic profile, and outcomes in patients with upper gastrointestinal bleed.
\end{abstract}

Methods: A descriptive cross-sectional study was conducted in a tertiary care teaching hospital in Gandaki Province, Nepal from January 2018 to December 2019 after obtaining ethical clearance from Institutional Review Committee (MEMG/IRC/291/GA) and informed consent from the patient or patient relatives. The sample size was calculated. Six hundred and sixty patients with upper gastrointestinal bleed were included in the study. Data entry was done in Statistical Packages for the Social Sciences version 20.

Results: Peptic ulcers and ruptured oesophageal varices are the common aetiologies of upper gastrointestinal bleed. Inpatient mortality was seen in 98 (14.8 \%) patients. Upper gastrointestinal bleed of variceal etiology presents with a higher Rockall score and has more chances of rebleeding and has higher mortality than those with non-variceal aetiologies. Bad prognostic factors were rebleeding, variceal etiology, and comorbidities including cirrhotic and Rockall score $>6$.

Conclusions: Upper gastrointestinal bleeding is a common acute medical emergency. Early upper gastrointestinal endoscopy preferably within 24 hours is recommended for diagnosis, timely intervention, and management of the patients with an upper gastrointestinal bleed that helps in reducing morbidity and mortality.

Keywords: endoscopy; esophageal and gastric varices; peptic ulcer; upper gastrointestinal tract.

\section{INTRODUCTION}

Upper gastrointestinal (UGI) bleed is defined as bleeding proximal to the ligament of Treitz. ${ }^{1}$ It is one of the common medical emergencies that have an incidence of 50 to 150 cases per 100000 population and hospital mortality of approximately $7 \%$ to $10 \%$ even in developed countries. ${ }^{2,3}$ Endoscopy is the gold standard diagnostic and therapeutic tool in the management of UGI bleed.
Non-variceal UGI bleeding is the most common cause where peptic ulcer disease accounts for $50 \%$ to $70 \% .{ }^{4}$ Rebleeding after hospital admission is associated

with higher mortality. Rockall Scoring system can be

Correspondence: Dr. Subash Bhattarai, Unit of Medical Gastroenterology, Department of Medicine, Manipal College of Medical Sciences and Teaching Hospital, Pokhara, Nepal. Email: kiwisubash@yahoo.com, Phone: +977-9815293117. 
Bhattarai et al. Clinical Profile and Endoscopic Findings in Patients with Upper Gastrointestinal Bleed Attending a Tertiary Care ...

used to predict the rebleeding and prognosis in patients with UGI bleed. ${ }^{5}$ A descriptive cross-sectional study regarding upper gastrointestinal bleeding is scanty from this region of Nepal.

In the present study, we will try to identify the prevalence, etiology of acute UGI bleed, clinical profiles of the patients including clinical outcomes and mortality in patients admitted in a tertiary care Hospital in Gandaki Province, Nepal.

\section{METHODS}

This descriptive cross-sectional study was carried out in the Unit of Medical Gastroenterology, Department of Medicine at a tertiary care Teaching Hospital at Pokhara, Gandaki Province, Nepal of 24 months duration period from January 2018 to December 2019.

The sample size was collected using the formula,

$$
\begin{aligned}
\mathrm{n} & =\left(\mathrm{Z}^{2} \times \mathrm{p} \times \mathrm{q}\right) / \mathrm{e}^{2} \\
& =\left(1.96^{2} \times 0.5 \times 0.5\right) / 0.05^{2} \\
& =384.16 \sim 385
\end{aligned}
$$

where,

$$
\begin{aligned}
& Z=1.96(\text { At } 95 \% \text { confidence interval) } \\
& p=\text { taking } 50 \% \text { prevalence } \\
& q=1-p \\
& e=\text { margin of error, } 5 \%
\end{aligned}
$$

The calculated minimum sample size was 385. A total of 2880 endoscopies were performed in 24 months which was the sample size more than adequate for the study.

Cases were studied from the records of the endoscopy unit and departmental records of admission and discharge summaries. Patients who presented with a history suggestive of acute upper gastrointestinal bleeding i.e. haematemesis, melena, or syncope were hospitalized randomly irrespective of age, sex, or comorbidities in the emergency department, the hemodynamic assessment was done with careful measurement of pulse and blood pressure including orthostatic changes and urine output. Patients were first hemodynamically stabilized; blood transfusion was given when required. Data considering demographic variables, clinical features, bleeding characteristics were collected and alongside blood investigations like complete blood count, platelets count, blood grouping, liver function test, prothrombin time/international normalized ratio (PT/ INR), coagulation profile and ultrasonography of abdomen reports were recorded.

After hemodynamic stability, usually within 24 hours, each patient had undergone endoscopic investigation by standard flexible gastro duodenal endoscope (PENTAX EPK 700, PENTAX JAPAN Inc) and diagnostic findings were documented. The lesion with recent stigmata of hemorrhage or active bleeding was considered the cause of bleeding when various lesions were found in UGI endoscopy. For control of bleeding, pharmacologic and endoscopic treatments were used. Non-variceal bleeders were treated with continuous intravenous infusion of proton pump inhibitor for at least 72 hours and ulcer healing agents. Variceal bleeders were treated with injection terlipressin/octreotide +/-variceal band ligation. The biopsy was performed in all patients with growth, ulcers, mucosal erosions, and areas suspicious to harbor neoplasia.

Finally, the clinical presentation of patients, their endoscopic findings, complications during hospitalization including rebleeding, days of ICU stay, total hospital stay, outcomes, and mortality were assessed. All patients with acute upper GI bleed aged above 16 irrespective of sex and presentation were included in the study. The following cases were excluded from the study: 1 . Patients with incomplete records 2 . The same patient readmitted and endoscopy showing the same endoscopic finding in readmissions.

The study was approved and verified by the Institutional Review Committee and the work was following the rules and regulations laid down by the Institutional Review Committee. Informed consent was obtained from patients or patient relatives. Data were collected on a structured proforma covering the relevant subjects of the study and entry was done in Statistical Packages for the Social Sciences version 20. All categorical data were expressed in percent and absolute number. All numerical continuous data were expressed in mean $\pm S D$. The data analysis was done using SPSS version 20. All tests were analyzed with a $95 \%$ confidence interval.

\section{RESULTS}

The total upper Gl endoscopies performed was 2880 during the 24 months of the study period from January 2018 till December 2019. Out of these 2880 sample study, 720 patients presented with an upper GI bleed, detecting a prevalence of $25 \%$.

But 24 patients were taken away to home or elsewhere by patient relatives against medical advice despite initial management, UGI endoscopy, and few days of admission, and 16 were excluded because of inadequate data. Twenty patients were readmitted with an upper GI bleed but had the same endoscopic findings as in previous endoscopies and admissions. Finally, a total of 660 patients; 384 (58.2\%) males, and 276 (41.8\%) females $(M: F=1.4: 1)$ were enrolled in the study. The mean age of subjects was $49 \pm 12.64$ years with a range of 14-88 years of age. Patients were further classified as per age/sex groups with maximum cases 
Bhattarai et al. Clinical Profile and Endoscopic Findings in Patients with Upper Gastrointestinal Bleed Attending a Tertiary Care ...

in 40-59 years of age group (Table 1 ).

\begin{tabular}{|llllll|}
\hline Table & 1. & Age groups/sex distribution of patient's understudy. \\
\hline SEX & \multicolumn{7}{c|}{ Age groups } \\
& $<40$ yrs & $40-59$ yrs & $60-79$ yrs & $\geq 80$ yrs & Total \\
MALE & 134 & 195 & 43 & 12 & 384 \\
FEMALE & 96 & 137 & 37 & 6 & 276 \\
\hline
\end{tabular}

These patients were classified according to their ethnicity/caste. The majority comprised of 210 (31.8\%) Mongols followed by $122(18.4 \%)$ Chhetris, 111 (16.8\%) Dalits, 87 (13.2\%) Newars, and $50(7.6 \%)$, Brahmins. Other caste included 80 (12.2\%) patients.

These patients were classified as per their occupation. The majority of these patients were 223 (33.8\%) farmers followed by $180(27.2 \%)$ retired personnel, $161(24.4 \%)$ jobholders, and 96 (14.6\%) housewives.

The majority comprising of $385(58.4 \%)$ patients were from rural areas whereas the rest $275(42.6 \%)$ belonged to urban regions. The majority comprising of 396 (60\%) patients were from middle socioeconomic status.

Risk factors in the study participants include smoking in 396 (60\%), chronic and regular alcohol consumption in 360 (54.5\%), recent consumption (within a week) of NSAIDs and steroids in $132(20 \%)$ and history of jaundice in 158 (24\%).

In the present study, $570(86.4 \%)$ patients had some form of comorbid conditions (Table 2).

\begin{tabular}{|ll|}
\hline \multicolumn{2}{|l|}{ Table 2. Comorbidities of the study subjects. } \\
\hline Comorbidities & $\mathbf{n}(\%)$ \\
Chronic liver disease liver & $300(45.5)$ \\
chronic kidney disease & $20(3)$ \\
Ischemic heart disease & $64(9.7)$ \\
History of CVA & $36(5.5)$ \\
COPD / Bronchial Asthma & $18(2.7)$ \\
Arthritis & $28(4.2)$ \\
Diabetes Mellitus & $40(6)$ \\
Hypertension & $50(7.6)$ \\
Pregnancy & $14(2.1)$ \\
No significant past medical history & $90(13.7)$ \\
Total & $660(100)$ \\
\hline
\end{tabular}

Chronic liver disease is seen in 300 (45.5\%) patients, was the most common comorbid condition identified. Chronic alcohol consumption leading to alcoholic liver disease was the most common etiology of chronic liver disease and seen in 276 (92\%) patients. Chronic viral hepatitis was etiology in 16 cases (5.2\%; Chronic Hep B $3.7 \%$ and chronic Hep C 1.5\%). Rest 8 (2.8\%) patients were classified as cryptogenic.

Two hundred and sixty-four (40\%) patients presented with only malena, $201(30.5 \%)$ with both haematemesis and malena, and $135(20.5 \%)$ presented with only haematemesis. The rest $60(9 \%)$ had a history of dizziness, generalized weakness. Stool for occult blood was positive in these cases. A total of 126 (19\%) patients presented with shock.

Among the clinical signs at presentation, pallor was the most common finding in $528(80 \%)$, followed by abdominal tenderness in $385(58.36 \%)$, splenomegaly in $300(45.4 \%)$, ascites in $240(36.4 \%)$, clinically icterus in $280(42.4 \%)$ and hepatomegaly in $83(12.6$ $\%)$ patients. Mean hemoglobin at presentation was 7.3 gm\% (range of $3.2 \mathrm{gm} \%$ to $14 \mathrm{gm} \mathrm{\% )}$ ). Haemoglobin was $<10 \mathrm{gm} \%$ in $476(72.16 \%)$ subjects. The mean platelet count was $96,000 / \mathrm{mm}^{3}$ with a minimum of $10,000 / \mathrm{mm}^{3}$ and a maximum of $5,10,000 / \mathrm{mm}^{3}$.

In the majority comprising of 580 (87.9\%) study participants, random blood sugar levels were normal, and blood urea and creatinine were raised in almost half of the patients. Liver function tests revealed hyperbilirubinemia in $300(45.4 \%)$ patients and increased ALT, AST, and prolonged prothrombin time by more than $4 \mathrm{sec}$ in 350 (53\%), 380 (57.6 \%), and $320(48.5 \%)$ patients respectively.

Peptic ulcer disease was the most common cause of upper GI bleed and was detected in 236 (35.7\%) patients (Table 3 ). Peptic ulcer was seen almost equally among both the sexes with a mean age of $36 \pm 8.25$ years. Duodenal ulcer was more common than gastric ulcer in both the sexes. They were further classified according to Forrest classification. Ten $(4.2 \%)$ had oozing hemorrhage, $32(13.6 \%)$ had an adherent clot, $839(35.1 \%)$ had haematin on ulcer base and rest 111 $(47.1 \%)$ had clean ulcer base and were classified as Forrest IB, IIB, IIC and III respectively. Eight out of 10 $(80 \%)$ patients were injected injection adrenaline for hemostasis in oozing bleeders that stopped ongoing bleed.

Variceal bleed was the second most common cause of upper GI bleed and was detected in 224 (33.9\%) (Table 3). Varices were more common in males (M: $\mathrm{F}=2.3: 1$ ) with a mean age of $49 \pm 8.34$ years. One hundred and eighty-six (83\%) patients were cirrhotics, predominantly alcohol-induced; $20(8.9 \%)$ were alcoholic hepatitis, and rest $18(8.1 \%)$ patients were 
Bhattarai et al. Clinical Profile and Endoscopic Findings in Patients with Upper Gastrointestinal Bleed Attending a Tertiary Care ...

classified as noncirrhotic portal hypertension. Variceal bleed was predominantly from ruptured oesophageal varices. Out of 224 variceal bleeds, 215 (96\%) bled from ruptured oesophageal varices. Endoscopic Oesophageal variceal band ligation was applied in 133 $(59.4 \%)$ with stigmata of ongoing bleed or varices to likely rebleed or with large varices.

Bleeding from portal hypertensive gastropathy, Mallory Weiss tear, and erosive mucosal disease accounted in $40(6.1 \%), 22(3.3 \%)$, and $62(9.4 \%)$ subjects respectively (Table 3 ). The common erosive mucosal disease was erosive gastritis followed by oesophagitis and duodenitis. No source of bleeding could be identified in $34(5.2 \%)$ patients by upper GI endoscopy. Upper GI malignancy was seen in 42 patients and accounted for $6.4 \%$. Upper GI malignancies were more common in males $(M: F=4: 3)$ with a mean age of $67 \pm 8.19$ years. Thirty $(71.4 \%)$ patients were aged between $60-79$ years of age. Five cases were aged below 40 years and they all had carcinoma of the stomach. The youngest patient was a 34 year male with gastric carcinoma. The most common upper GI malignancy over all ages and in both the sexes was carcinoma of stomach followed by oesophageal and duodenal. A gastrointestinal stromal tumor (GIST) was seen in $5(0.7 \%)$ patients.

\begin{tabular}{|c|c|c|c|c|}
\hline Etiology of UGI bleed & Male & Female & Total & $\%$ \\
\hline Gastro-oesophageal varices & 156 & 68 & 224 & 33.9 \\
\hline Oesophageal Varices & 150 & 65 & 215 & 32.6 \\
\hline Gastric varices & 6 & 3 & 9 & 1.3 \\
\hline Peptic ulcer diseases & 120 & 116 & 236 & 35.7 \\
\hline Duodenal ulcer & 66 & 62 & 128 & 19.4 \\
\hline Gastric ulcer & 54 & 54 & 108 & 16.3 \\
\hline Portal Hypertensive Gastropathy & 24 & 16 & 40 & 6.1 \\
\hline Erosive mucosal lesions & 36 & 26 & 62 & 9.4 \\
\hline Erosive gastritis & 15 & 11 & 26 & 3.9 \\
\hline Erosive oesophagitis & 13 & 11 & 23 & 3.5 \\
\hline Erosive duodenitis & 8 & 5 & 13 & 2 \\
\hline Mallory Weiss tear & 10 & 12 & 22 & 3.3 \\
\hline GI malignancies & 24 & 18 & 42 & 6.4 \\
\hline Gastric carcinoma & 12 & 10 & 22 & 3.4 \\
\hline Oesophageal Carcinoma & 6 & 5 & 11 & 1.7 \\
\hline Duodenal Carcinoma & 2 & 2 & 4 & 0.6 \\
\hline GIST & 4 & 1 & 5 & 0.7 \\
\hline None identified & 14 & 20 & 34 & 5.2 \\
\hline TOTAL & 384 & 276 & 660 & 100 \\
\hline
\end{tabular}

Among 360 alcoholics and patients with chronic liver diseases, bleeding from ruptured gastroesophageal varices were commoner than peptic ulcer bleed. Bleeding from ruptured varices, peptic ulcer, portal hypertensive gastropathy, mucosal erosive disease, MWT were seen in 153(42.5\%), 139 (38.6\%), 29 $(8.1 \%), 19(5.2 \%), 10(2.8 \%)$ respectively. Among rest $10(2.8 \%)$, no source of bleeding could be identified by UGI endoscopy.

Mean complete Rockall score after UGI endoscopy in all the subjects under study was $4.86 \pm 1.18$. One Hundred and seventy-two (26\%) had Rockall score more than or equal to 5 .

Ninety-eight (14.8\%) patients with upper Gl bleed had inpatient mortality. Two third of the mortality accounting to 74 in number occurred within 7 days. Cirrhotics with complications and variceal bleeders accounted for 72 mortalities. Only 4 mortalities occurred in patients with peptic ulcer bleed. Twelve mortalities occurred in patients with $\mathrm{Gl}$ malignancies. The rest 10 mortalities occurred in patients with pre-existing comorbidities. The most common causes of mortality were rebleeding in $29(29.6 \%)$ within 48 hours followed by hepatic encephalopathy in $24(24.5 \%)$ hepatorenal syndrome in $22(22.5 \%)$ and sepsis in $14(14.3 \%)$. Hypovolaemic 
Bhattarai et al. Clinical Profile and Endoscopic Findings in Patients with Upper Gastrointestinal Bleed Attending a Tertiary Care ...

and cardiogenic shock, congestive cardiac failure, spontaneous bacterial peritonitis, and aspiration pneumonia were less common causes of mortality and seen in $9(9.1 \%)$ patients. All of the patients who died had Rockall score $>6$. More mortalities were observed with rebleeding, variceal bleeders, comorbidities including cirrhotics, GI malignancies, and Rockall score $>6$ (Table 4).

Endoscopic interventions in the form of injecting adrenaline were done in 6 peptic ulcer bleeders and endoscopic oesophageal variceal band ligation in 133 patients. No surgical intervention of any kind was necessary for this study. The median hospital stay was $6.178+2.11$ days. The median ICU stay was $3.21+1.37$ days. Five hundred and sixty-two (85.2\%) patients recovered after needful management and treatment and were discharged from the hospital.

Male predominance (M: $F=2.3: 1)$ was noted in subjects with variceal bleed. Patients with the variceal bleed group presenting in shock were double than those with a non-variceal bleed group. Mean complete Rockall score after UGI endoscopy was $5.66 \pm 1.20$ in a variceal group and $4.06 \pm 0.98$ in the non-variceal group. Rockall score more than or equal to 5 was 3 times more in the variceal group compared to no variceal bleeders. Rebleeding within 7 days was higher and 3 times more with variceal group compared to that with a non-variceal group (30\% vs $10 \%)$. Similarly, mortality was also higher and almost 5 times more with variceal group compared to that with a non-variceal group $(31.25 \%$ vs $6.4 \%)$. (Table 5 )

\begin{tabular}{|lccl|}
\hline \multicolumn{4}{|l|}{$\begin{array}{l}\text { Table 4. Factors associated with mortality in } \\
\text { patients with UGI bleed. }\end{array}$} \\
\hline Parameters & Total & Discharged & $\begin{array}{l}\text { Mortality } \\
(\%)\end{array}$ \\
Rebleeding & 29 & 8 & $21(72.4)$ \\
$\begin{array}{l}\text { Rockall score } \\
>6\end{array}$ & 140 & 82 & $\begin{array}{l}58 \\
(41.4)\end{array}$ \\
$\begin{array}{l}\text { Co morbid } \\
\text { conditions }\end{array}$ & 570 & 334 & $\begin{array}{l}236 \\
(41.4)\end{array}$ \\
$\begin{array}{l}\text { GI } \\
\text { malignancies }\end{array}$ & 36 & 24 & $\begin{array}{l}12 \\
(33.3)\end{array}$ \\
Variceal bleed & 224 & 154 & $\begin{array}{l}70 \\
(31.2)\end{array}$ \\
Cirrhotics & 300 & 224 & $\begin{array}{l}76 \\
(25.3)\end{array}$ \\
Non Cirrhotics & 360 & 338 & $22(6.1)$ \\
\hline
\end{tabular}

\begin{tabular}{|c|c|c|}
\hline Parameters & $\begin{array}{l}\text { Variceal bleed } \\
\text { group n (\%) }\end{array}$ & $\begin{array}{l}\text { Non-variceal } \\
\text { bleed group } \\
\mathrm{n}(\%)\end{array}$ \\
\hline Male: Female & 2.3:1 & $1.1: 1$ \\
\hline $\begin{array}{l}\text { Mean } \\
\text { Haemoglobin }\end{array}$ & $6.71 \pm 1.63$ & $8.18 \pm 1.48$ \\
\hline $\begin{array}{l}\text { Platelets count } \\
<90000 / \mathrm{mm}^{3}\end{array}$ & $144(64.3)$ & $46(10.6)$ \\
\hline $\begin{array}{l}\text { PT prolonged by } \\
>4 \mathrm{sec}\end{array}$ & 176 (78.6) & $54(12.4)$ \\
\hline $\begin{array}{l}\text { Shock }(\text { SBP }<90 \\
\mathrm{mm} \mathrm{Hg})\end{array}$ & $64(28.6)$ & $62(14.2)$ \\
\hline $\begin{array}{l}\text { Mean Rockall } \\
\text { score }\end{array}$ & $5.66 \pm 1.20$ & $4.06 \pm 0.98$ \\
\hline $\begin{array}{l}\text { Rockall score } \\
>5\end{array}$ & 30 (37.5) & $5(12.5)$ \\
\hline $\begin{array}{l}\text { Rebleeding } \\
\text { within } 7 \text { days }\end{array}$ & $24(30)$ & $4(10)$ \\
\hline Death & 70 (31.25) & $28(6.4)$ \\
\hline
\end{tabular}

\section{DISCUSSION}

The mean age of subjects was $49 \pm 12.64$ years with a range of $14-88$ years of age with male dominance in this study. Varied age groups at presentation with UGI bleed have been mentioned in various literature. Anand et al. ${ }^{6}$ Rao et al. ${ }^{7}$ and Salih et $a^{8}$ reported mean ages of 41,43 and 44.6 years respectively. Kaliamurthy et al. ${ }^{9}$ reported higher mean age of 55 years. A published UK audit showed an even higher mean age of 64.4 years. ${ }^{10}$ Studies reported by Gurung et al. ${ }^{11}$ in Dhulikhel, Nepal, and Dewan et al. ${ }^{12}$ in Chitwan, Nepal showed mean ages of $45.32 \pm 18.47$ and $48.76 \pm 17.19$ years respectively which are almost similar to the finding in the current study. The male predominance of $79 \%$ and $59 \%$ were observed in a Sudan study by Salih et al. ${ }^{7}$ and UK audit ${ }^{10}$ respectively. The male predominance of $75 \%$ and $78.4 \%$ were reported by Dewan et al. ${ }^{12}$ and Kashyap et al. ${ }^{13}$ in Nepal. The current study also showed the male predominance of $70 \%$ which was marginally less compared to the previous studies in Nepal.

Peptic ulcer disease was the most common cause of upper $\mathrm{Gl}$ bleed and was detected in 236 (35.7\%) patients in the current study. Whereas, studies by Anand et al., ${ }^{6}$ Jain et al. ${ }^{14}$ and Rao et al. ${ }^{7}$ reported esophageal varices as the most common cause of UGI bleed and found that the incidence was $45.5 \%, 47.4 \%$, and $51 \%$ respectively. The study by Dewan et al. ${ }^{12}$ in Chitwan, Nepal also revealed that esophageal varices $(47.5 \%)$ were the most common cause of UGI bleed. This was followed by peptic ulcer disease (33.3\%), 
erosive mucosal disease $(11.6 \%)$, Mallory Weiss tear $(4.1 \%)$ and malignancy $(3.3 \%) .{ }^{12}$

The incidence of peptic ulcer bled reported by Anand et al. ${ }^{6}$ and Rao et al. ${ }^{7}$ were $38.5 \%$ and $28 \%$ respectively. Peptic ulcer bleeds accounting to $41 \%$ was the common cause reported by Kaliamurthy et al. ${ }^{9}$ from Jamaica. The incidence of peptic ulcer bleed was $36 \%$ in a UK audit ${ }^{10}$ and $30.6 \%$ by Bhutta et al. ${ }^{15}$ Peptic ulcer disease detected in $35.7 \%$ was the most common cause of upper GI bleed followed by $33.9 \%$ of variceal bleeds in the current study.

Bleeding from erosive mucosal disease was $9.4 \%$ in the current study. Anand et al. ${ }^{6}$ and Rao et al. ${ }^{7}$ found the erosive mucosal disease in $8.5 \%$ and $9 \%$ respectively. The incidence rates were almost similar in the abovementioned studies. But Bhutta et al. ${ }^{15}$ found a higher incidence rate of $18.4 \%$. Bleeding from Mallory Weiss tear was found to be $3.3 \%$ in the current study. Kashyap et al. ${ }^{13}$ reported Mallory Weiss to tear as a cause of upper GI bleeding in 12 patients $(10.8 \%)$ and Bhutta et al. ${ }^{15}$ reported it in 2 patients $(1.4 \%)$.

Bleeding from upper GI malignancy was $6.4 \%$ in the current study. It was reported to be $5.9 \%$ and $3.3 \%$ in the studies by Jain et al. ${ }^{14}$ in India and Dewan et al. ${ }^{12}$ in Chitwan, Nepal respectively. No etiology of upper Gl bleed was identified in $5.2 \%$ in the current study. Whereas, $16.1 \%$ had normal endoscopic findings in an Indian study by Jain et al. ${ }^{14}$

Mean hemoglobin at presentation was $7.3 \mathrm{gm} \%$ in the current study. It was $8.4 \mathrm{gm} \%$ in the study by Jain et al. ${ }^{14}$

Among 380 chronic alcohol consumers and patients with chronic liver diseases, bleeding from ruptured gastroesophageal varices was the most common cause of bleed followed by peptic ulcer bleed in our current study. Bleeding from ruptured varices, peptic ulcer, portal hypertensive gastropathy, mucosal erosive disease, MWT were seen in 153 (42.5\%), 139 (38.6\%), $29(8.1 \%), 19(5.2 \%), 10(2.8 \%)$ respectively. In a similar study in central Nepal by Bhattarai et al., ${ }^{16}$ ruptured oesophageal varices $(66.7 \%)$ was the most common cause of UGI bleeding in patients with chronic liver disease followed by peptic ulcer bleeding in $19.2 \%$.

In the current study, $40 \%$ of patients presented with only malena, $30.5 \%$ with both haematemesis and malena, and $20.5 \%$ presented with the only haematemesis. The rest $9 \%$ had a history of dizziness and generalized weakness. A total of $19 \%$ of patients presented with shock in the current study. In the study by Dewan et al., ${ }^{12}$ both haematemesis and malena was seen in $71.7 \%$, only malena in $20 \%$ and only haematemesis in $8.3 \%$ at presentation. Shock was detected in $21.7 \%$ of patients with UGI bleed in that study.

Among patients with chronic liver disease and variceal bleed, this subset of patients presented with severe anemia, shock, and more complications. Rockall score was higher, rebleeding rates were more (30\% vs $10 \%$ ) and higher mortality almost 5 -fold $(31.25 \%$ vs $6.4 \%$ ) was recorded in variceal bleeders on comparison with non-variceal bleed in the current study. Similar were the findings in the study done by Bhattarai et al. ${ }^{16}$ in central Nepal with increased mortality amongst variceal bleeders (27.5 \% vs. $7.5 \%$ ). Similarly, mortality was higher in variceal bleed group $(20.2 \%$ vs $6.9 \%)$ in the study by Svoboda et al. ${ }^{17}$

In the current study, the overall mortality was seen in 98 (14.8\%) patients. Salih et al. ${ }^{8}$ investigated 238 patients and found a mortality rate of $3.4 \%$. Kashyap et al. ${ }^{13}$ studied 111 patients in India and showed an overall mortality rate of $3.6 \%$ and all patients had esophageal variceal bleed. Kaliamurthy et al. ${ }^{9}$ reported a mortality rate of $5.7 \%$, whereas UK Audit $2007^{10}$ reported a mortality of $10 \%$. Mortality of $4.2 \%$ was reported in the study by Dewan et al. in Chitwan, Nepal. The mortality rate was higher in the current study when compared to the above mentioned studies.

The median hospital stay was $6.178 \pm 2.11$ days in the current study whereas, it was $7.28 \pm 3.18$ days in the study by Dewan et al. ${ }^{12}$ Rebleeeding, presence of comorbidities and Rockall score $>6$ were the identifiable risk factors for mortality in the study by Dewan et al. ${ }^{12}$ These risk factors were also associated with mortality in our study patients. Advanced age $>60$ years, variceal bleeders, deranged coagulation profile, prolonged prothrombin time, thrombocytopenia were the other factors associated with mortality in the current study.

This study had its limitations. The study reflects a certain geographical area. Most of the patients had no repeat endoscopies records on follow-ups. Etiology of UGI bleed could not be identified in some subjects because of the unavailability of enteroscopy, capsule endoscopy, and other needful modalities. Early and appropriate fluid and pharmacological management alongside upper $\mathrm{GI}$ endoscopy preferably within 24 hours are recommended for diagnosis, timely intervention, and management of the patients with UGI bleed that helps in reducing morbidity and mortality. More expertise with training and availability of diagnostic and therapeutic endoscopies in the majority of hospitals 
Bhattarai et al. Clinical Profile and Endoscopic Findings in Patients with Upper Gastrointestinal Bleed Attending a Tertiary Care ...

will help in reducing complications and mortality secondary to UGI bleed. This study may help formulate guidelines for proper and needful management of upper gastrointestinal bleed.

\section{CONCLUSIONS}

Peptic ulcers and ruptured oesophageal varices were common aetiologies of upper Gl bleed. Inpatient mortality was seen in $98(14.8 \%)$ patients. UGI bleed of variceal etiology presented with a higher Rockall score and had more rebleeding and had higher mortality than those with non-variceal aetiologies. Bad prognostic factors were advanced age $>60$ years, massive rebleeding, variceal bleeders, deranged coagulation profile, prolonged prothrombin time, thrombocytopenia, comorbidities including cirrhotics and Rockall score $>6$. Furthermore, the Rockall score is an effective tool for outcome prediction in patients with acute upper Gl bleeding.

Conflict of Interest: None.

\section{REFERENCES}

1. FallahMA,PrakashC,EdmundowiczS. Acutegastrointestinal bleeding. Med Clin North Am. 2000;84(5):1183-208. [PubMed | Full Text | DOI]

2. Yavorski RT, Wong RK, Maydonovitch C, Battin LS, Furnia A, Amundson DE. Analysis of 3,294 cases of upper gastrointestinal bleeding in military medical facilities. Am J Gastroenterol. 1995;90(4):568-73. [PubMed]

3. Hearnshaw SA, Logan RFA, Lowe D, Travis SPL, Murphy MF, Palmero KR. Use of endoscopy for management of acute upper gastrointestinal bleeding in the UK: result of a nationwide audit. Gut. 2010;59(8):1022-9. [PubMed | Full $\underline{\text { Text }} \mid \underline{\text { DOI] }}$

4. Marshall JK, Collins SM, Gafni A. Prediction of resource utilization and case cost for acute nonvariceal upper gastrointestinal hemorrhage at a Canadian community hospital. Am J Gastroenterol. 1999;94(7):1841-46. [․ㅏbMed | Full Text]

5. Rockall TA, Logan RF, Devlin HB, Northfield TC. Risk assessment after acute upper gastrointestinal haemorrhage. Gut.1996;38(3):16-21. [PubMed | Full Text | DOI]

6. Anand CS, Tandon BN, Nundy S. The causes, management and outcome of upper gastrointestinal haemorrhage in an Indian hospital. British Journal of Surgery.1983;70(4):209-11. [PubMed | Full Text | DOI]

7. Rao THSG, Pande GK, Sahni P, Nundy S. The management of upper gastrointestinal haemorrhage in a tropical country. Archives of Emergency Medicine. 1991;8(3):169-76. [PubMed | Full Text $\mid \underline{\text { DOI] }}$

8. Salih H, Ibnouf M.A.M, Siddig A, Masaad A. Rockall score of the acute upper gastrointestinal bleeding patients the experience in Sudan. Sudan JMS. 2009;4(3):232-6. [․ㅏll Text [ DOI]

9. Kaliamurthy M, Lee MG, Mills M, Murphy T. Upper gastrointestinal bleeding: a jamaican perspective. West Indian Med J. 2011;60(3):289-92. [라bMed | Full Text]
10. Hearnshaw SA, Logan RFA, Lowe D, Travis SPL, Murphy MF, Palmer KR. Acute upper gastrointestinal bleeding in the UK: patient characteristics, diagnoses and outcomes in the 2007 UK audit. Gut. 2011;60(10):1327-35. [uuMed | Full $\underline{\text { Text }} \mid \underline{\text { DOI] }}$

11. Gurung RB, Joshi G, Gautam N, Pant P, Pokhrel B, Koju $\mathrm{R}$, et al. Upper gastro-intestinal bleeding: aetiology and demographic profile based on endoscopic examination at dhulikhel hospital, kathmandu university hospital. Kathmandu University Medical Journal. 2010;8(2): 208-11. [PubMed | Full Text | DOI]

12. Dewan KR, Patowary BS, Bhattarai S. A study of clinical and endoscopic profile of acute upper gastrointestinal bleeding. Kathmandu Univ Med J 2014;12(1):21-25. [PubMed | Full $\underline{\text { Text }} \mid \underline{\text { DOI] }}$

13. Kashyap R, Mahajan S, Sharma B, Jaret P, Patial RK, Rana S, et al. Clinical profile of acute upper gastrointestinal bleeding at moderate altitude. JIACM. 2005;6(3):224-8. [Full Text]

14. Jain J, Rawool A, Banait S, Maliye C. Clinical and endoscopic profile of the patients with upper gastrointestinal bleeding in central rural India: A hospital based cross sectional study. J Mahatma Gandhi Inst Med Sci 2018;23(1):13-8. [Full Text | DOI]

15. Bhutta S, Jamil M, Aziz K, Uddin W. An etiological study of upper gastrointestinal bleeding. JRMC. 2012;16(1):31. [․ㅡll Text]

16. Bhattarai S, Dewan KR, Shrestha G, Patowary BS. Spectrum of upper gastrointestinal bleed in patients with cirrhosis of liver. JCMS-Nepal. 2017;13(3):318-22. [Full Text | DOI]

17. Svoboda P, Konecny M, Martinek A, Hrabovsky V, Prochazka V, Ehrmann J. Acute upper gastrointestinal bleeding in liver cirrhosis patients. Biomed Pap Med Fac Univ Palacky Olomouc Czech Repub. 2012;156(3):266-70.

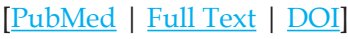

The Author(s) 2018

This work is licensed under a Creative Commons Attribution 4.0 International License. The images or other third party material in this article are included in the article's Creative Commons license, unless indicated otherwise in the credit line; if the material is not included under the Creative Commons license, users will need to obtain permission from the license holder to reproduce the material. To view a copy of this license, visit http://creativecommons.org/licenses/by/4.0/ 